\title{
Gamma Radiation Shielding Properties of Slag and Fly Ash-based Geopolymers
}

\author{
M. W. Hassan ${ }^{1}$, S. Sugiharto ${ }^{2}$, S. Astutiningsih ${ }^{1 *}$ \\ ${ }^{1}$ Department of Metallurgical and Materials Engineering, Faculty of Engineering, Universitas Indonesia, Depok 16424, Indonesia \\ ${ }^{2}$ Center for Isotopes and Radiation Application, National Nuclear Energy Agency (BATAN), \\ Jl. Lebak Bulus Raya No. 49, Jakarta 12440, Indonesia.
}

\section{ARTICLE INFO}

Article history:

Received 6 July 2020

Received in revised form 22 March 2021

Accepted 24 March 2021

Keywords:

Geopolymer

Radiation Shielding

Attenuation Coefficient

Half-value Layer

Tenth-value Layer

\section{A B S T R A C T}

Industrial waste-based geopolymer cement is a greener alternative to Ordinary Portland Cement (OPC) for radiation shielding with comparable mechanical properties without the production of $\mathrm{CO}_{2}$ during synthesis. In this paper, the linear attenuation coefficient of slag and fly ash-based geopolymers, unmodified by aggregates, is measured and used to calculate the mass attenuation coefficients, half-value layer (HVL), and tenth-value layer (TVL) of the geopolymers. Narrow Beam Gamma Spectrometry with gamma energy of $0.662 \mathrm{MeV}, 1.173 \mathrm{MeV}$, and $1.332 \mathrm{MeV}$ was used to irradiate a series of slag and fly ash-based geopolymer paste of cylindrical shape with a diameter of $7.5 \mathrm{~cm}$ and height of $9.5 \mathrm{~cm}$. Slag geopolymer has linear attenuation coefficient of $0.1642 / \mathrm{cm}, 0.1237 / \mathrm{cm}$, $0.1150 / \mathrm{cm}$, mass attenuation coefficient of $0.0782 \mathrm{~cm}^{2} / \mathrm{g}, 0.0589 \mathrm{~cm}^{2} / \mathrm{g}, 0.0548 \mathrm{~cm}^{2} / \mathrm{g}$, the HVL of $4.222 \mathrm{~cm}, 5.609 \mathrm{~cm}, 6.056 \mathrm{~cm}$, and TVL of $14.025 \mathrm{~cm}, 18.633 \mathrm{~cm}$, $20.118 \mathrm{~cm}$, respectively. Fly ash geopolymer has linear attenuation coefficient of $0.1387 / \mathrm{cm}, 0.1075 / \mathrm{cm}$, and $0.0964 / \mathrm{cm}$, mass attenuation coefficient of $0.0761 \mathrm{~cm}^{2} / \mathrm{g}$, $0.0589 \mathrm{~cm}^{2} / \mathrm{g}, 0.0529 \mathrm{~cm}^{2} / \mathrm{g}, \mathrm{HVL}$ of $4.998 \mathrm{~cm}, 6.453 \mathrm{~cm}, 7.202 \mathrm{~cm}$, and TVL of $16.603 \mathrm{~cm}, 21.437 \mathrm{~cm}, 23.926 \mathrm{~cm}$, respectively. Test samples made from slag-based geopolymers have a better shielding capability compared to fly ash-based geopolymers due to having higher attenuation coefficients as well as lower HVL and TVL, thus requiring less material to absorb radiation of the same energy level.

(C) 2021 Atom Indonesia. All rights reserved

\section{INTRODUCTION}

The modern world relies on the utilization of high-energy ionizing radiation in various sectors such as medical diagnostics, chemical analysis, power generation, and industrial processing. X-rays and Gamma rays that are commonly utilized for those purposes are not without risks to human operators and may result in unwanted problems such as cell damage, mutations, and cancer from excessive exposures [1]. Radiation shielding is used to absorb high-energy radiation so that the human operators behind them will stay safe and sound [1]. Conventionally, Portland Concrete is used as radiation shielding due to its convenient and widespread usage in construction, while still providing the necessary protection from radiation. However, in addition to cost and shielding ability, consideration such as environmental sustainability is

\footnotetext{
*Corresponding author.

E-mail address: sotya.astutiningsih@ui.ac.id

DOI: https://doi.org/10.17146/aij.2021.1076
}

another viable concern for the selection of shielding materials.

Conventional Portland concrete is considered to be environmentally unfriendly since it uses Ordinary Portland Cement (OPC) as its binder. Mineral powders used as OPC raw materials generally consist of calcareous minerals or calciumbased minerals, with $\mathrm{CaO}$ levels around 60-65 \% [2]. Cumulative Emissions of $\mathrm{CO}_{2}$ by cement production from 1928 to 2018 into the atmosphere were $38.3 \pm 2.4$ metric gigatons $(\mathrm{Gt})$ of $\mathrm{CO}_{2}, 71 \%$ of which have occurred since 1990, while $1.50 \pm 0.12 \mathrm{Gt}$ of $\mathrm{CO}_{2}$ was released in 2018 [3]. This is primarily caused by the calcination process in which calcium carbonate is heated (by burning hydrocarbons in the form of fossil fuels) so that it breaks down into calcium oxide and releases $\mathrm{CO}_{2}$ to create the clinker which is the main component of cement [3]. The combustion of fuels involved to heat the reaction in addition to the main chemical process also contributes significantly to the overall emission of cement production, which could be as large as 
$8 \%$ of global $\mathrm{CO}_{2}$ emission [3]. Other key polluting substances emitted to air during cement production include carbon monoxide (CO), nitrogen oxides $(\mathrm{NOx})$, sulfur dioxide $\left(\mathrm{SO}_{2}\right)$, volatile organic compounds, dust, and particulate matter [4].

To overcome the environmental issue caused by Portland cement production, geopolymer concrete can be used as a substitute. The binder used in geopolymer concrete is a geopolymer gel made from inorganic minerals, typically aluminosilicates. The hardening mechanism in geopolymer occurs through polycondensation which forms a crosslinking structure and releases water [5]. Clay, slag, and fly ash are some of the materials that can be used as geopolymer precursors [5]. Besides having comparable properties to conventional cement, geopolymer is comparably environmentally friendly due to its reactions being $\mathrm{CO}_{2}$ free, and because the aluminosilicate precursor being easily obtainable from industrial wastes such as metal slag or fly ash resulted from the combustion of rice husks and coal carried by residual gas [3,5]. Geopolymers are also superior in their ability to harden faster than conventional concrete, with promising strength and durability for radiation shielding [5].

Generally studied research topics on geopolymers are related to the types of precursors being used (metakaolin, fly ash slag, etc.), their properties, and their applications. There is also an interest in the potential of geopolymer as well as the effect of waste materials in radiation shielding, but typically focusing on the use of additional radiation absorbent aggregates to the geopolymer matrix [68]. Similar aggregates as well as other types of aggregates have also been studied for use in conventional and heavy concrete [9-11].

The ability of geopolymer to be used as a radiation shield can be measured by linear attenuation coefficient which is then used to calculate other parameters: mass attenuation coefficient, the thickness of the material at which the intensity of radiation is reduced by one half or known as half-value layer (HVL), and the thickness of the material at which the intensity of radiation is reduced by $90 \%$ or known as tenth-value layer (TVL) [1].

This study aimed to investigate the value of these parameters for nickel slag-based and fly ashbased-geopolymer paste, unmodified by other additional aggregates, which are then exposed to gamma beams of various energy levels. The effect of paste density, as the main differentiator of geopolymer precursors, was also investigated for the four variables. The radiation protection ability of geopolymers based on these four variables will be compared with conventional OPC paste concrete from available literature [12].

\section{THEORY/CALCULATION}

Geopolymers are amorphous 3-dimensional semicrystalline structures formed through polycondensation of aluminosilicates with alkaline solutions [13,14]. At present, the alkalis that have been studied are $\mathrm{Na}$ and $\mathrm{K}$. Geopolymers can be express by the pseudo chemical formula,

$$
\mathrm{M}_{\mathrm{n}}\left\{---\left(\mathrm{SiO}_{2}\right)_{\mathrm{z}^{---}} \mathrm{AlO}_{2}\right\} \cdot \mathrm{wH}_{2} \mathrm{O}
$$

where $\mathrm{M}$ is a cation of alkali, $\mathrm{n}$ is the degree of polycondensation, and $\mathrm{z}$ is the ratio of $\mathrm{Si}$ and $\mathrm{Al}, \mathrm{w}$ is the mole ratio of the water that is bound and can be released during structural rearrangement while hardening $[13,14]$. The form of the geopolymer is a gel mixture consisting of a network of Al-O-SI molecules $[2,13,14]$. The structure is a 3dimensional network in which $\mathrm{SiO}_{4}$ and $\mathrm{AlO}_{4}$ bind to $\mathrm{O}$ atoms used together with the $\mathrm{Al}$ Coordination in IV-fold and this causes a negative charge so it needs to be balanced with the alkaline cation $[2,13,14]$. The structure is shown in Fig. 1.

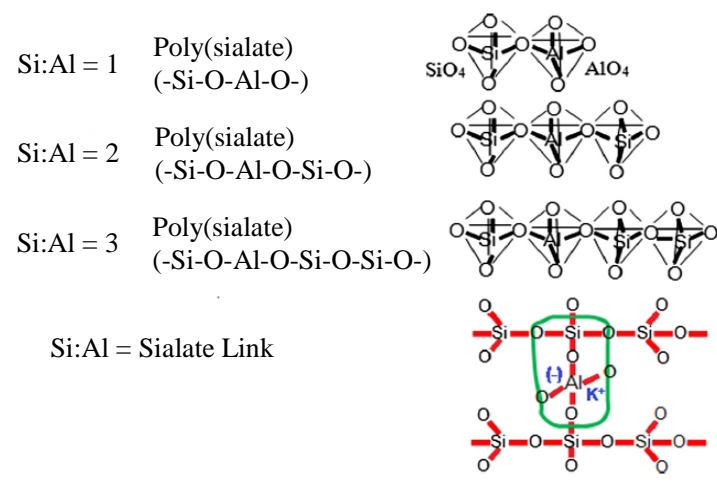

Fig. 1. Types of network structures in geopolymers [13].

Geopolymerization is the reaction between aluminosilicate precursors $\left(\mathrm{Si}_{2} \mathrm{O}_{5}, \mathrm{Al}_{2} \mathrm{O}_{2}\right)$ in an IVfold coordination structure, with $\mathrm{SiO}_{2}$ originated from a silicate solution. This reaction is exothermic and will produce a geopolymer backbone in the form of Si-O-Al chains. Hydroxyl $(\mathrm{OH})$ ion species in the solution will isolate aluminosilicate precursors and the addition of water also contributes to this role $[2,13,14]$.
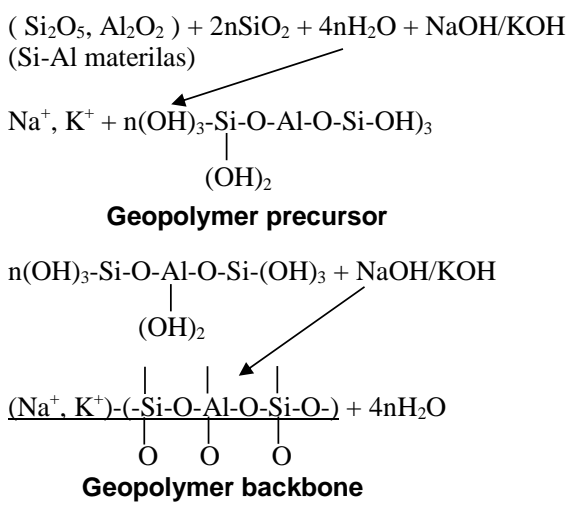

Fig. 2. Geopolymerization reaction [13]. 
As illustrated in Fig. 2, initially an intermediate gel precursor will be formed, which then undergoes polycondensation in the form of a cross-linking between the intermediate gels followed by the release of water, rearrangement of repetitive structure, and complemented with charge balancing by alkaline ions [13].

To evaluate the performance of geopolymer for radiation shielding, its linear attenuation coefficient is measured. The linear attenuation coefficient $(\mu)$ can be obtained from the natural log division of the ratio of ray intensity that can be transmitted to the intensity of the initial ray, with the distance traveled in the form of medium thickness $[1,6]$. This ratio is also referred to as the transmission rate. Equation (1) describes the attenuation coefficient of a medium independently of particles and distance and also explains the relationship between the atomic number and the mass of the medium to that coefficient $[1,6,7]$.

$$
\mu=\mathrm{N} \sigma=\sigma \frac{\rho \mathrm{N}_{\mathrm{a}}}{A}
$$

where $\sigma$ is the proportionality constant of the interaction in the form of effective cross-sections of interaction space, $\mathrm{N}$ is the number of particles in one atomic medium in volume units and $\mathrm{A}$ is the area of interaction [1]. The rate of linear attenuation coefficient to density is the mass attenuation coefficient and makes it an intrinsic property of the medium that is independent of density. Equation (2) illustrates the mass attenuation coefficient $[1,6,7]$

$$
\frac{\mu}{\rho}=\sigma \frac{\mathrm{N}_{\mathrm{a}}}{A}
$$

The mass attenuation coefficient can also be defined as an area of transverse attenuation interaction for a unit weight of absorbed material so that it is more often used in medical or biological applications. In the protection against gamma radiation, the concept of HVL and TVL are commonly used to evaluate the ability of the medium in radiation protection. HVL represents the thickness of a shield that reduces the radiation level by a factor of one-half. It can be calculated by the Eq. (3) below $[1,6,7]$.

$$
\mathrm{X}_{1 / 2}=\frac{\operatorname{Ln} 2}{\mu}
$$

Meanwhile, TVL is the thickness of a shield that reduces the radiation level by a factor of one-tenth of the initial level. It can be calculated by the Eq. (4) below [1].

$$
\mathrm{X}_{1 / 10}=\frac{\operatorname{Ln} 10}{\mu}
$$

\section{EXPERIMENTAL METHODS}

\section{Materials}

Two types of precursors were used as raw materials for geopolymer. The first was slag in the form of powder from the manufacturing process of nickel pig iron in PT Indoferro [14]. The second was fly ash from coal combustion and carried by combustion gas in Suralaya Steam Fired Power Plant. XRF testing was done at LIPI PUSPIPTEK Serpong Physics Research Center to obtain the

\begin{tabular}{|c|c|c|}
\hline & Slag & Fly Ash \\
\hline Constituent & $\% \mathrm{WT}$ & $\% \mathrm{WT}$ \\
\hline $\mathrm{SiO}_{2}$ & 41.24 & 50.41 \\
\hline $\mathrm{CaO}$ & 24.71 & 6 \\
\hline $\mathrm{MgO}$ & 19.29 & 2.15 \\
\hline $\mathrm{Al}_{2} \mathrm{O}_{3}$ & 9.69 & 24.54 \\
\hline $\mathrm{Fe}_{2} \mathrm{O}_{3}$ & 1.71 & 10.89 \\
\hline $\mathrm{SO}_{3}$ & 0.9 & 0.68 \\
\hline $\mathrm{MnO}$ & 0.83 & 0.15 \\
\hline $\mathrm{Cr}_{2} \mathrm{O}_{3}$ & 0.67 & 0.03 \\
\hline $\mathrm{TiO}_{2}$ & 0.26 & 0.93 \\
\hline $\mathrm{Na}_{2} \mathrm{O}$ & 0.24 & 2.47 \\
\hline $\mathrm{K}_{2} \mathrm{O}$ & 0.17 & 1.02 \\
\hline $\mathrm{Sc}_{2} \mathrm{O}_{3}$ & 0.11 & 0.02 \\
\hline $\mathrm{SrO}$ & 0.11 & 0.18 \\
\hline $\mathrm{V}_{2} \mathrm{O}_{5}$ & 0.03 & 0.03 \\
\hline $\mathrm{ZnO}$ & 0.02 & 0.03 \\
\hline $\mathrm{NiO}$ & 0.01 & 0.01 \\
\hline $\mathrm{ZrO}_{2}$ & 0.01 & 0.06 \\
\hline $\mathrm{P}_{2} \mathrm{O}_{5}$ & 0 & 0.1 \\
\hline $\mathrm{As}_{2} \mathrm{O}_{3}$ & 0 & 0.01 \\
\hline $\mathrm{Y}_{2} \mathrm{O}_{3}$ & 0 & 0.01 \\
\hline $\mathrm{BaO}$ & 0 & 0.11 \\
\hline Trace & 0 & 0.17 \\
\hline TOTAL & 100 & 100 \\
\hline
\end{tabular}
composition of the precursors presented in Table 1.

Table 1. The XRF testing result of geopolymer precursor as a percentage of weight $(\% \mathrm{WT})$

The alkaline activator used was a solution of mixed soda flakes $(\mathrm{NaOH}$ or Sodium Hydroxide) with Water Glass $\mathrm{Na}_{2} \mathrm{SiO}_{3}$ (Sodium Silicate) in water, with the composition according to patent No. P000043023. Silica sand used was in the form of a fine aggregate.

\section{Preparation of slag and fly ash paste sample}

All raw materials were weighed and then mixed by using a mixer. The resulting sludge will be 
cast into a $7.5 \mathrm{~cm}$ diameter metal mold with a height of $9.5 \mathrm{~cm}$ and allowed to harden.

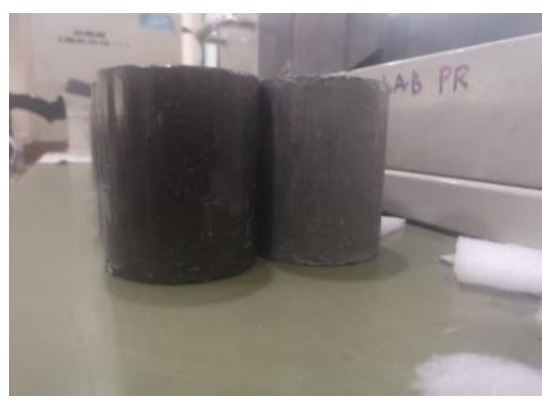

Fig. 3. Geopolymer paste after hardening (slag-based on the left, fly ash-based on the right).

Six slag pastes and six fly ash pastes were made with a thickness of $7.5 \mathrm{~cm}$, to give a series of cumulative thickness of $7.5 \mathrm{~cm} 15 \mathrm{~cm}, 22.5 \mathrm{~cm}, 30$ $\mathrm{cm}, 37.5 \mathrm{~cm}$, and $45 \mathrm{~cm}$ for gamma spectroscopy testing. A compressive strength test is carried out at the Structure Laboratory of the Department of Civil Engineering Universitas Indonesia on samples of similar dimensions and compositions. Figure 3 shows both types of geopolymer paste after being solidified, with the Slag-based paste being significantly darker in colour.

\section{Characterization/gamma spectrometry}

To evaluate the ability of samples in attenuating gamma radiation, gamma rays are transmitted from a radioisotope source through a test object by Narrow Beam Gamma Spectrometry. This test is called Narrow Beam because the radioisotope is located in a lead collimator where the gamma beam can only be channeled through a small gap intensity in one direction. Measurement of linear attenuation coefficient was conducted in Radiation Protection Laboratory, Center for Education and Training, BATAN. As the measurement process involved gamma radiation, sufficient protective measures such as personal protective equipment and radiation dosage monitoring are done according to the standard operating procedures.

The distance between the source and the detector was $47 \mathrm{~cm}$, the number of channels at MCA was 1024 , the voltage used was $800 \mathrm{~V}$. The radioisotope used was $50 \mathrm{mCi}{ }^{137} \mathrm{Cs}$ with gamma energy of $0.662 \mathrm{MeV}$ and $5 \mathrm{mCi}{ }^{60} \mathrm{Co}$ with gamma energy of $1.117 \mathrm{MeV}$ and $1.332 \mathrm{MeV}$ for each type of geopolymer paste with variations in distance. The accumulation time of measurement for both sources was 180 seconds.

\section{RESULTS AND DISCUSSION Weight, dimension, and density}

After the paste was hardened, the diameter and mass were measured to calculate the actual dimension and density of the paste. The density used is obtained by dividing the measured volume with the measured mass. The data is shown in Table 2.

Table 2. The actual dimension, weight, and density.

\begin{tabular}{lrrrrr}
\hline $\begin{array}{l}\text { Precu- } \\
\text { Rsor }\end{array}$ & $\begin{array}{c}\text { Diameter } \\
(\mathbf{c m})\end{array}$ & $\begin{array}{c}\text { Height } \\
(\mathbf{c m})\end{array}$ & $\begin{array}{c}\text { Mass } \\
(\mathbf{g})\end{array}$ & $\begin{array}{l}\text { Density } \\
(\mathbf{g} / \mathbf{c m 3})\end{array}$ & $\begin{array}{c}\text { Average } \\
\text { Density } \\
(\mathbf{g} / \mathbf{c m})\end{array}$ \\
\hline Slag & 7.48 & 9.24 & 853 & 2.100778 & \\
\cline { 1 - 5 } & 7.5 & 9.45 & 880 & 2.107835 & \\
& 7.55 & 9.32 & 871 & 2.087478 & 2.09728 \\
& 7.515 & 9.32 & 859 & 2.089109 & \\
& 7.53 & 9.47 & 880 & 2.086643 & \\
& 7.515 & 9.32 & 873 & 2.111807 & \\
& 7.55 & 9.45 & 776 & 1.834212 & \\
& 7.56 & 9.35 & 757 & 1.803626 & \\
& 7.575 & 9.365 & 764 & 1.810212 & 1.82385 \\
& 7.55 & 9.35 & 767 & 1.832298 & \\
& 7.52 & 9.365 & 772 & 1.856037 & \\
& 7.57 & 9.42 & 766 & 1.806732 & \\
\hline
\end{tabular}

From Table 2, it can be shown that there is a slight difference between the size of the mold and the actual size of the paste. The discrepancy is due to the imperfection in the pouring process and the existence of trapped air that caused the porosity inside the paste.

\section{Transmission rate and material thickness}

It has been known that the initial intensity of radiation will be greater with the increase of radiation dose, but the contained energy remains the same. Radiation dose only shows the amount of radiation, while energy shows how strong the power is being delivered. As a result, cobalt radioisotope will tend to penetrate easier through a certain material compared to cesium, even though the dose is smaller. The energy used is limited to the photoelectric spectrum, so the interactions that occur as well as the attenuation coefficient to be obtained only cover the photoelectric process.

The information given in Table 3 shows that for all sample variations, a relationship is obtained for increasing cumulative material thickness. The intensity of the radiation that penetrates an absorbing material will decrease exponentially, according to the Beer-Lambert law. It is also seen that increase in radiation energy for the same 
absorber will increase the transmission rate. When compared based on the type of material and in terms of its density, the denser the absorber, the smaller the transmission rate.

Table 3. Relationship between Transmission Rate and Material Thickness at various energies.

\begin{tabular}{|c|c|c|c|}
\hline \multicolumn{4}{|c|}{$\begin{array}{l}\text { Slag-based Geopolymer } \\
\left(2.09727507595165 \mathrm{~g} / \mathrm{cm}^{3}\right)\end{array}$} \\
\hline Energy & $\begin{array}{l}\mathbf{0 . 6 6 2} \\
\mathrm{MeV}\end{array}$ & $\begin{array}{l}\text { 1.173- } \\
\mathrm{MeV}\end{array}$ & 1.332 MeV \\
\hline Thickness & \multicolumn{3}{|c|}{ Transmission Rate } \\
\hline 0 & 1.0000 & 1.0000 & 1.0000 \\
\hline 7.48 & 0.2941 & 0.375 & 0.38 \\
\hline 14.98 & 0.0857 & 0.1521 & 0.1787 \\
\hline 22.53 & 0.0252 & 0.0614 & 0.0711 \\
\hline 30.05 & 0.0072 & 0.0285 & 0.0313 \\
\hline 37.58 & 0.002 & 0.0103 & 0.0151 \\
\hline 45.09 & 0.0006 & 0.0042 & 0.0102 \\
\hline \multicolumn{4}{|c|}{$\begin{array}{c}\text { Fly Ash-based Geopolymer } \\
\left(1.8238528132607 \mathrm{~g} / \mathrm{cm}^{3}\right)\end{array}$} \\
\hline Energy & $\begin{array}{l}\mathbf{0 . 6 6 2} \\
\mathrm{MeV}\end{array}$ & $\begin{array}{l}1.173 \\
\mathrm{MeV}\end{array}$ & 1.332 MeV \\
\hline Thickness & \multicolumn{3}{|c|}{ Transmission Rate } \\
\hline 0 & 1.0000 & 1.0000 & 1.0000 \\
\hline 7.55 & 0.3519 & 0.4377 & 0.4804 \\
\hline 15.11 & 0.1234 & 0.2003 & 0.2119 \\
\hline 22.69 & 0.0432 & 0.0868 & 0.1185 \\
\hline 30.24 & 0.0151 & 0.0458 & 0.0499 \\
\hline 37.76 & 0.0053 & 0.014 & 0.0297 \\
\hline 45.33 & 0.0018 & 0.008 & 0.0153 \\
\hline
\end{tabular}

The data in Table 3 is then converted into a graph of the relationship between thickness and transmission rate, so that evidence can be obtained regarding the tendency of exponential weakening. The graph tendency obtained by regression can also be used to obtain attenuation coefficients because the equation of the curve form $\mathrm{y}=\mathrm{e}^{-\mathrm{mx}}$ is analogous to the Beer-Lambert law, where the attenuation coefficient is symbolized as the value of $\mathrm{m}$. Figure 4 also presents the graph of absorption of each type of material for each energy.

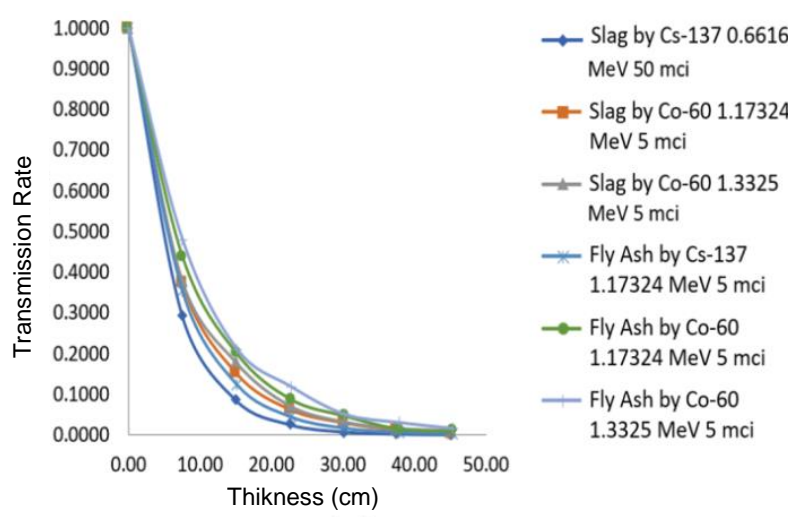

Fig. 4. Correlation between Transmission Rate and Thickness.
The difference between each line is the distance (thickness) where the attenuation reduced drastically. It can be seen from the depth of the curve which is symbolized by the value of $m$ in the curve equation. The higher the value of $\mathrm{m}$, the deeper the curve. From the curve, it can also be seen from the tendency that density is inversely proportional to the radiation energy received by the sample. Thus, the curve will shift more towards the center which indicated that the weakening ability increases and the minimum thickness attenuation decrease.

\section{Attenuation, HVL, and TVL based on Beer-Lambert law}

The parameters of mass attenuation coefficient, HVL, and TVL are also calculated by Beer-Lamber Law. The result is shown in Table 4.

Table 4. Calculated attenuation coefficient, HVL, and TVL using Beer-Lambert Law.

\begin{tabular}{|c|c|c|c|}
\hline \multicolumn{4}{|c|}{ Slag-based Geopolymer $\left(2.09727507595165 \mathrm{~g} / \mathrm{cm}^{3}\right)$} \\
\hline Energy & $\begin{array}{l}0.662 \\
\mathrm{MeV} \\
\end{array}$ & $\begin{array}{l}1.173 \\
\mathrm{MeV} \\
\end{array}$ & $1.332 \mathrm{MeV}$ \\
\hline $\begin{array}{l}\text { Linear Attenuation } \\
\text { Coefficient }\left(\mathrm{cm}^{-1}\right)\end{array}$ & 0.1642 & 0.1237 & 0.115 \\
\hline $\begin{array}{l}\text { Mass Attenuation } \\
\text { Coefficient }\left(\mathrm{cm}^{2} / \mathrm{g}\right)\end{array}$ & 0.0782 & 0.0589 & 0.0548 \\
\hline HVL $(\mathrm{cm})$ & 4.2219 & 5.6091 & 6.0561 \\
\hline TVL $(\mathrm{cm})$ & 14.0249 & 18.633 & 20.1178 \\
\hline \multicolumn{4}{|c|}{ Fly Ash-based Geopolymer (1.8238528132607 g/cm $\left.{ }^{3}\right)$} \\
\hline Energy & $\begin{array}{l}0.662 \\
\text { MeV }\end{array}$ & $\begin{array}{l}1.173 \\
\text { MeV }\end{array}$ & $1.332 \mathrm{MeV}$ \\
\hline $\begin{array}{l}\text { Linear Attenuation } \\
\text { Coefficient }\left(\mathrm{cm}^{-1}\right)\end{array}$ & 0.1387 & 0.1075 & 0.0964 \\
\hline $\begin{array}{l}\text { Mass Attenuation } \\
\text { Coefficient }\left(\mathrm{cm}^{2} / \mathrm{g}\right)\end{array}$ & 0.0761 & 0.0589 & 0.0528 \\
\hline HVL $(\mathrm{cm})$ & 4.9979 & 6.4532 & 7.2023 \\
\hline TVL (cm) & 16.6027 & 21.437 & 23.9257 \\
\hline
\end{tabular}

Based on the Beer-Lambert Law, for ${ }^{137} \mathrm{Cs}$ $0.662 \mathrm{MeV},{ }^{60} \mathrm{Co} 1.173 \mathrm{MeV}$, and ${ }^{60} \mathrm{Co} 1.332 \mathrm{MeV}$, slag geopolymer has linear attenuation coefficients of $0.1642 / \mathrm{cm}, 0.1237 / \mathrm{cm}, 0.1150 / \mathrm{cm}$, respectively. Whereas the fly ash-based-geopolymer has a linear attenuation coefficient of $0.1387 / \mathrm{cm}, 0.1075 / \mathrm{cm}$, $0.0964 / \mathrm{cm}$ respectively. A high linear attenuation coefficient indicates the likelihood of a high attenuation occurring at a certain distance. In the case of geopolymer, slag paste has a higher likelihood of weakening the radiation than fly ash pastes for the same radiation energy.

The data on the linear attenuation coefficients were then used to calculate the mass attenuation coefficient. Based on the Beer-Lambert Law, 
for ${ }^{137} \mathrm{Cs}$ of $0.662 \mathrm{MeV},{ }^{60} \mathrm{Co}$ of $1.173 \mathrm{MeV}$, and ${ }^{60} \mathrm{Co}$ of $1.332 \mathrm{MeV}$, the slag geopolymer has a mass attenuation coefficient of $0.0782 \mathrm{~cm}^{2} / \mathrm{g}$, $0.0589 \mathrm{~cm}^{2} / \mathrm{g}$, and $0.0548 \mathrm{~cm}^{2} / \mathrm{g}$, whereas the fly ash geopolymer has mass attenuation coefficient of $0.0761 \mathrm{~cm}^{2} / \mathrm{g}, 0.0589 \mathrm{~cm}^{2} / \mathrm{g}$, and $0.0528 \mathrm{~cm}^{2} / \mathrm{g}$ respectively. A high mass attenuation coefficient indicates a high area of weakening interaction for a unit mass. In the case of geopolymers, slag paste has a slightly higher area of weakening interaction than fly ash paste for ${ }^{137} \mathrm{Cs}$ of $0.662 \mathrm{MeV}$ and ${ }^{60} \mathrm{Co}$ of $1.332 \mathrm{MeV}$ but is similar for ${ }^{60} \mathrm{Co}$ of $1.173 \mathrm{MeV}$.

The values of HVL and TVL were calculated using Eqs. $(3,4)$. The results were inversely proportional to the linear and mass attenuation coefficients, and directly proportional to radiation energy being absorbed. Based on the Beer-Lambert $\mathrm{Law}$, for ${ }^{137} \mathrm{Cs} 0.662 \mathrm{MeV},{ }^{60} \mathrm{Co} 1.173 \mathrm{MeV}$, and ${ }^{60} \mathrm{Co} 1.332 \mathrm{MeV}$, slag geopolymer has HVL of $4.2219 \mathrm{~cm}, 5.6091 \mathrm{~cm}, 6.0561 \mathrm{~cm}$, and TVL of $14.0249 \mathrm{~cm}, 18.6330 \mathrm{~cm}, 20.1117 \mathrm{~cm}$, respectively. Whereas, the fly ash geopolymer has HVL of 4.9979 $\mathrm{cm}, 6.4532 \mathrm{~cm}, 7.2023 \mathrm{~cm}$, and TVL of $16.6027 \mathrm{~cm}$, $21.4370 \mathrm{~cm}, 23.9257 \mathrm{~cm}$, respectively. Small HVL and TVL values indicate that the distance needed for weakening gamma interaction within the material are also proportionately small. In the case of geopolymers, slag paste has a smaller distance required for attenuation compared to that of fly ash pastes.

\section{Comparison between geopolymer and conventional concrete}

Information on the radiation protection capability obtained in this work was compared to conventional concrete, the values of which were obtained from certain literature. Due to limited data for local conventional concrete types, a comparison was done with conventional concrete from Jordan [12], as shown in Table 5.

For all variations of radioisotope energy, slag geopolymers have superior attenuation, HVL, and TVL coefficients compared to fly ash geopolymer and conventional Jordan concrete. For cesium radiation, the lowest absorption ability is shown by conventional Jordan concrete, with a considerable difference from slag geopolymer. As for cobalt radiation, the overall ability of Jordan concrete is not much different from the ability of slag geopolymer and far superior to fly ash geopolymer.
Table 5. Value of Linear and mass attenuation coefficient, HVL, and TVL compared to other concrete.

\begin{tabular}{ccccc}
\hline \multirow{2}{*}{$\begin{array}{c}\text { Radio- } \\
\text { Isotope }\end{array}$} & Variable & Slag-based & $\begin{array}{c}\text { Fly Ash- } \\
\text { based }\end{array}$ & $\begin{array}{c}\text { Gordan's } \\
\text { Convention-al } \\
\text { Concrete [12] }\end{array}$ \\
\cline { 3 - 4 } & Linear & 0.1642 & 0.1387 & 0.1380 \\
${ }^{137} \mathrm{Cs}$ & Mass & 0.0782 & 0.0761 & 0.0730 \\
$0.662 \mathrm{MeV}$ & HVL & 4.2219 & 4.9979 & 5.0510 \\
& TVL & 14.0249 & 16.6027 & 16.6854 \\
\hline & Linear & 0.1237 & 0.1075 & 0.1230 \\
${ }^{60} \mathrm{Co}$ & Mass & 0.0589 & 0.0589 & 0.0660 \\
1.17324 & HVL & 5.6091 & 6.4532 & 5.6310 \\
$\mathrm{MeV}$ & TVL & 18.6330 & 21.4370 & 18.7202 \\
\hline & Linear & 0.1150 & 0.0964 & 0.1120 \\
& Mass & 0.0548 & 0.0529 & 0.0600 \\
${ }^{60} \mathrm{Co}$ & HVL & 6.0561 & 7.2023 & 6.1980 \\
\hline${ }^{1.3325 \mathrm{MeV}}$ & TVL & 20.1178 & 23.9257 & 20.5588 \\
\hline & & & &
\end{tabular}

\section{Discussion}

Geopolymer has a great potential to replace conventional concrete as the radiation shielding concrete. From the study, it is generally shown that the attenuation coefficient for gamma radiation in nickel slag paste is greater than the fly ash paste, whereas HVL and TVL in nickel slag paste are smaller. This is due to the density in which is inversely proportional to the value of HVL and TVL. As a result, the slag paste geopolymer is overall better than fly ash pastes for reducing gamma radiation intensity. This trend holds for all radiation energy levels, except for mass attenuation coefficient when exposed to ${ }^{60} \mathrm{Co}$ of $1.173 \mathrm{MeV}$, having the same value of $0.0589 \mathrm{~cm}^{2} / \mathrm{g}$.

When both are compared with conventional Jordan concrete, the trendline observed is inconsistent between energy levels. Only for ${ }^{137} \mathrm{Cs}$ of $0.662 \mathrm{MeV}$ that an increase in linear attenuation similarly increases mass attenuation while decreasing both HVL and TVL. The order of shielding capability for all parameters is consistent, with slag-based geopolymer as the best option, followed by fly ash-based geopolymer and lastly Jordan concrete, albeit the second and third-ranked is not far in value from each other.

For ${ }^{60} \mathrm{Co}$ of $1.173 \mathrm{MeV}$, and ${ }^{60} \mathrm{Co}$ of 1.332 $\mathrm{MeV}$, the order for shielding capability parameters become less consistent between each other. Slag-based geopolymer and Jordan concrete have similar linear attenuation values but both are far greater than the fly ash-based geopolymer's. However, when comparing mass attenuation 
coefficient, Jordan concrete is far superior compared to both geopolymers, where between slag-based and fly ash-based the value is the same for ${ }^{60} \mathrm{Co}$ of 1.173 $\mathrm{MeV}$ but not for ${ }^{60} \mathrm{Co}$ of $1.332 \mathrm{MeV}$. Except for mass attenuation coefficient, the order of shielding capability for the rest of the parameters become the following; first is slag-based geopolymer, followed by Jordan concrete, and the last is fly ash-based as the least protective against cobalt radioisotope,

To explain the difference in the radiation shielding behavior between geopolymer and conventional Portland cement, the chemical composition and microstructure differences between the two must be taken into account. Geopolymer, depending on the precursor type, is composed of predominantly silica and magnesia for nickel slagbased, and silica and alumina for fly ash-based geopolymers [5]. On the other hand, OPC is mainly composed of calcia with lesser content of silica [2]. Geopolymer cured through polycondensation reaction has a network structure resembling that of an aluminosilicate glass but with the presence of molecular free water as a byproduct of the reaction [5]. Conversely, OPC is cured through hydration reaction resulting in the microstructure of calcium silicate hydrates growing and filling in the pores between unhydrated particles [2].

Within the geopolymer itself, the radiation absorption capacity varies due to the difference in the composition and the shape of the particles. As a result of vaporization and cooling, fly ash particles were formed into spherical shape. On the other hand, slag was ball-milled into powder resulting in irregular and angular particle shape characteristic of the conchoidal fracture of glass. Further research needs to be done to understand better the interaction between gamma rays with the types of element, the size and shapes of particles, and the types of water that exist within the barrier material.

Overall, slag geopolymers are superior when compared to both fly ash-based geopolymer and conventional Jordan concrete according to the obtained data where only the main paste is concerned. Concrete structures used for radiation protection made with slag geopolymers require less material and smaller size compared to the other concretes mentioned. The radiation shielding capability of the slag geopolymer should further improve compared to the baseline value obtained from this study if additional aggregates such as boron carbide [6], hematite [7], barite [8], mixture of barite and hematite [9], wolframite [10] or serpentine [11] are incorporated.

Radiation shielding is not only used to attenuate gamma radiation, other forms of ionizing radiation such as neutrons would also require some form of control. Water is a common medium used to moderate neutron in a nuclear reactor by reducing its kinetic energy [1], as such the effect of the types of water molecules within the cement microstructure on the radiation shielding properties should also be studied. This is relevant when comparing geopolymers with OPC because water molecules are present as hydrates within OPC, while they exist as free water molecules within geopolymer paste $[2,5]$.

Other fields for the continuation of this research include but are not limited to: the comparison of different age geopolymers, usage of other aluminosilicate precursors such as rice husks, exposure to other radioisotopes, and after-effects of radiation on geopolymer structure.

\section{CONCLUSION}

A series of experiments have been carried out to measure the physical properties of viable shielding candidates based on slag and fly-ash geopolymer materials. The linear attenuation coefficient of slag geopolymer are $0.1642 / \mathrm{cm}$, $0.1237 / \mathrm{cm}, \quad 0.1150 / \mathrm{cm}$, so that the mass attenuation coefficient is $0.0782 \mathrm{~cm}^{2} / \mathrm{g}$, $0.0589 \mathrm{~cm}^{2} / \mathrm{g}, 0.0548 \mathrm{~cm}^{2} / \mathrm{g}$, the HVL are $4.222 \mathrm{~cm}$, $5.609 \mathrm{~cm}, 6.056 \mathrm{~cm}$, and TVL are $14.025 \mathrm{~cm}$, $18.633 \mathrm{~cm}, 20.118 \mathrm{~cm}$, respectively. Meanwhile, the fly ash geopolymer has linear attenuation coefficient of $0.1387 / \mathrm{cm}, \quad 0.1075 / \mathrm{cm}, \quad$ and $0.0964 / \mathrm{cm}$, mass attenuation coefficient of 0.0761 $\mathrm{cm}^{2} / \mathrm{g}, \quad 0.0589 \mathrm{~cm}^{2} / \mathrm{g}, \quad 0.0529 \mathrm{~cm}^{2} / \mathrm{g}$, HVL of $4.998 \mathrm{~cm}, 6.453 \mathrm{~cm}, 7.202 \mathrm{~cm}$, and TVL of $16.603 \mathrm{~cm}$, $21.437 \mathrm{~cm}, 23.926 \mathrm{~cm}$, respectively. Test samples made from slag-based geopolymers have a better shielding capability compared to fly ash-based geopolymers due to having higher attenuation coefficients as well as lower HVL and TVL indicating that less material is needed to absorb radiation of the same energy level.

\section{ACKNOWLEDGMENT}

All authors wish to deliver their thanks to the Center for Education and Training, the Nuclear Energy Agency of Indonesia (BATAN) for providing certified spectrometry equipment for gamma rays attenuation measurement.

Authors also acknowledge that this research is partially funded by Universitas Indonesia under contract No. NKB-2474/UN2.RST/HKP.05.00/2020 and contract addendum No. NKB4967/UN2.RST/HKP.05.00/2020 Hibah PUTI Saintekes (Q4). 


\section{AUTHOR CONTRIBUTION}

Muhammad Widad Hassan contributed as the primary writer of this paper, responsible for conducting the experiment, data collection, and analysis. Sotya Astutiningsih contributed to the procurement of raw materials, tools, and additional data from previous experiments. Sugiharto contributed by providing access to the spectrometry equipment and the knowledge of operating them. All authors contributed to the research design, discussed the analysis results, read and approved the final version of the paper.

\section{REFERENCES}

1. J. K. Shultis and R. E. Faw, Fundamentals of Nuclear Science and Engineering, CRC Press, Florida (2017).

2. T. A. Aragaw, Concise Introduction to Cement Chemistry and Manufacturing; Synthesis Lectures on Engineering, Morgan\&Claypool, California (2018).

3. R. M. Andrew, Earth Syst. Sci. Data 11 (2019) 1675.

4. U. Arachchige, J. Devasurendra, L. Chathumini et al., Int. J. Res. 6 (2019) 631.
5. J. Davidovits, Geopolymer Chemistry and Applications $5^{\text {th }}$ Edition, Institut Géopolymère, Saint-Quentin, France (2020).

6. U. D. Prastiwi, Synthesis and Work Simulation of Concrete Composite based Nuclear Radiation Shielding against X-ray/Gamma Ray and Neuron Exposure, Institut Pertanian Bogor, Bogor (2017).

7. Nurhasmi, D. Tahir, B. Abdullah et.al., Mater. Sci. Forum 966 (2019) 41.

8. S. Shalbi, M. Jaafar, N. Alrawi et.al., IOSR J. Appl. Phys. 9 (2017) 51.

9. T. Shams, M. Eftekhar and A. Shirani, Constr. Build. Mater. 182 (2018) 35.

10. B. Aygün, J. Rad. Res. Appl. Sci. 12 (2019) 352.

11. M. A. Masoud, A. M. El-Khayatt, W. A. Kansouh et.al., Constr. Build. Mater. 263 (2020) 120141

12. M. Awadallah, M. M. A. Imran, J. Environ. Radioact. 94 (2007) 129

13. Y.-M. Liew, C.-Y. Heah, A. B. M. Mustafa et.al., Prog. Mater. Sci. 83 (2016) 595.

14. D. D. B. Nergis, M. M. A. B. Abdullah, P. Vizureanu et. al., IOP Conference Series: Material Science and Engineering 374 (2018) 012019

15. S. Astutiningsih, B. Suharno, $6^{\text {th }}$ International Slag Valorization Symposium (2019) 269. 